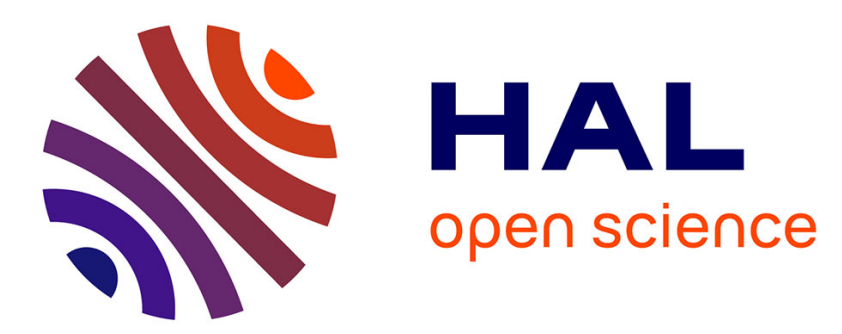

\title{
Electrofluorochromism of Surface-Confined Tetrazines Investigated on the Monolayer Scale
}

\author{
Laetitia Guerret-Legras, Baptiste Maillot, Jean Frédéric Audibert, G. V \\ Dubacheva, Laurent Galmiche, Philippe Lang, Fabien Miomandre
}

\section{To cite this version:}

Laetitia Guerret-Legras, Baptiste Maillot, Jean Frédéric Audibert, G. V Dubacheva, Laurent Galmiche, et al.. Electrofluorochromism of Surface-Confined Tetrazines Investigated on the Monolayer Scale. Journal of Physical Chemistry C, 2019, 123 (48), pp.29255-29261. 10.1021/acs.jpcc.9b08929 . hal-02395117

\section{HAL Id: hal-02395117 \\ https://hal-univ-paris.archives-ouvertes.fr/hal-02395117}

Submitted on 5 Dec 2019

HAL is a multi-disciplinary open access archive for the deposit and dissemination of scientific research documents, whether they are published or not. The documents may come from teaching and research institutions in France or abroad, or from public or private research centers.
L'archive ouverte pluridisciplinaire HAL, est destinée au dépôt et à la diffusion de documents scientifiques de niveau recherche, publiés ou non, émanant des établissements d'enseignement et de recherche français ou étrangers, des laboratoires publics ou privés. 


\title{
Electrofluorochromism of surface confined tetrazines investigated at the monolayer scale
}

\author{
L. Guerret-Legras ${ }^{1}$, B. Maillot ${ }^{1}$, J.F. Audibert ${ }^{1}$, G.V. Dubacheva ${ }^{1}$, L. Galmiche ${ }^{1}$, P. Lang ${ }^{2}$, F. \\ Miomandre 1* $^{*}$ \\ * mioman@ens-paris-saclay.fr \\ ${ }^{1}$ PPSM, CNRS, Ecole Normale Supérieure Paris-Saclay, 94235 Cachan (France) \\ ${ }^{2}$ ITODYS, CNRS, Université de Paris, 75013 Paris (France)
}

\section{Abstract}

Monolayers of tetrazine terminated alkyl chains have been grafted on ITO through siloxane functions. These monolayers are electroactive and display fluorescence with a maximum close to 560 $\mathrm{nm}$ when excited in the visible range. Potential step cycles have been applied and the fluorescence intensity drawn from background and bleaching corrected emission spectra was found to be switched off and on reversibly according to the applied potential. This demonstrates that the luminescence of grafted fluorophores can be electrochemically controlled as it is in solution and the emission intensity can be followed with a good signal to noise ratio even for a monolayer.
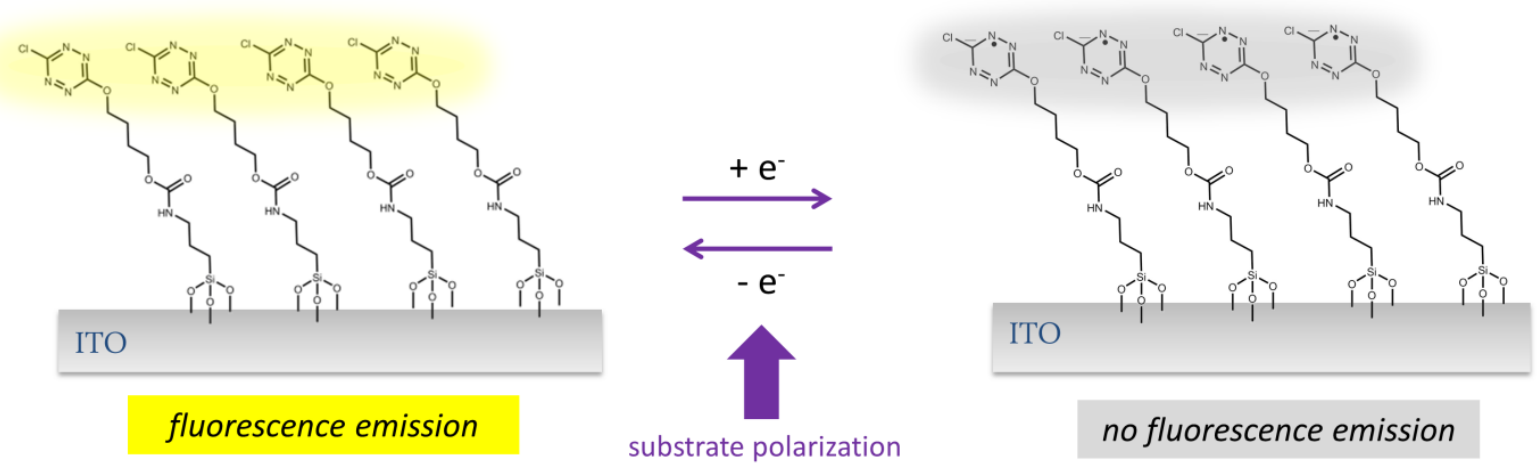

\section{Introduction}

The electrochemical switch of light emission, called electrofluorochromism has become a topic of interest especially in the past decade, because it opens new routes to control the optical properties of molecules and materials. The topic has been reviewed recently, highlighting the large number of molecular compounds likely to show this property as well as the instrumental set-up developed to investigate the process ${ }^{1-5}$. Up to now, most of the experimental works have been devoted to molecules in solution ${ }^{6}$ or more scarcely to bulk materials ${ }^{7}$ and examples of electrofluorochromism in solid state remain very rare $^{8}$ despite its major interest to design high contrast devices ${ }^{9-10}$. The 
detection of the phenomenon is based on either spectrofluoelectrochemistry in thin layer electrochemical cells $s^{11-14}$ or fluorescence microscopy (wide field ${ }^{15}$ or confocal ${ }^{16-17}$ ) and more recently $\mathrm{STM}^{18}$ which allows downsizing the detection to the single molecule level. If we except polymers ${ }^{19-24}$ with recent examples combining aggregation induced emission (AIE) pendant groups on a conjugated backbone $\mathrm{e}^{25-26}$ and nanoparticles $\mathrm{s}^{27-28}$, that can be easily deposited on electrode surfaces as thin films, there has been to our knowledge no example of electrofluorochromism investigated directly on surface confined molecular systems at the monolayer scale. Recent studies by Levillain et al. highlighted the fact that surface-confined molecular systems may behave differently from their counterparts in solution, due to specific interactions in the confined state ${ }^{29}$. Another challenge to overcome lies in the reliable detection of switching phenomena down to the monolayer scale, because the number of fluorophores is very low compared to solution and bleaching phenomena become a real issue. Self-assembled monolayers (SAMs) bearing redox active fluorescent terminal groups can be easily synthesized using well mastered techniques like Langmuir-Blodgett or simply self-assembly on surface by dip-coating or soaking. However, the only works found in the literature where fluorescence and electrochemical properties are simultaneously measured in situ on SAMs come mainly from Bizzotto et al. who used fluorophore-labeled DNA on gold and detection under fluorescence microscope ${ }^{30-31}$. Information about the structure and heterogeneity of the monolayer can be drawn from the coupling of optical and electrochemical techniques ${ }^{30}$. Moreover, as the fluorescence signal is very sensitive to the vicinity of the electrode surface, the electrochemically induced desorption can be easily detected by the emission intensity enhancement ${ }^{32-34}$. On our side, we mainly use this coupling to tune the luminescence output as a function of the electrode potential input in a reversible way, which is the basics of electrofluorochromism ${ }^{4}$. Therefore, we found it of high interest to demonstrate that electrofluorochromism can be triggered and detected on surface confined systems even at the monolayer scale.

To achieve that goal, an electrofluorochromic unit must be selected. Tetrazines are the smallest organic electroactive fluorophore units ${ }^{35}$ and they have proven their efficiency in the design of electrofluorochromic windows ${ }^{36}$. Moreover the possibility of grafting them on surfaces with an adequate anchoring group depending on the nature of the substrate was also reported ${ }^{37-38}$. In our case, as we use ITO as the working transparent electrode, a siloxane terminated tetrazine was selected, as its grafting efficiency was previously demonstrated on silica ${ }^{39}$ and titania ${ }^{28}$ nanoparticles. After proving the formation of monolayers of tetrazine derivative on the ITO surface using cyclic voltammetry and ATR-FTIR measurements, we report the first example of electrofluorochromism recorded by reversibly switching a monolayer. 


\section{Results and discussion}

3-Chloro-6(4-(3-(triethoxysilyl)propyl-carbamoyl-oxy)butoxy)-tetrazine (TEOSTz) was synthesized according to a procedure adapted from ref. ${ }^{39}$.

The tetrazine derivative is then grafted on activated ITO according to the reaction represented in scheme 1. The detailed experimental protocol is reported in S.I.

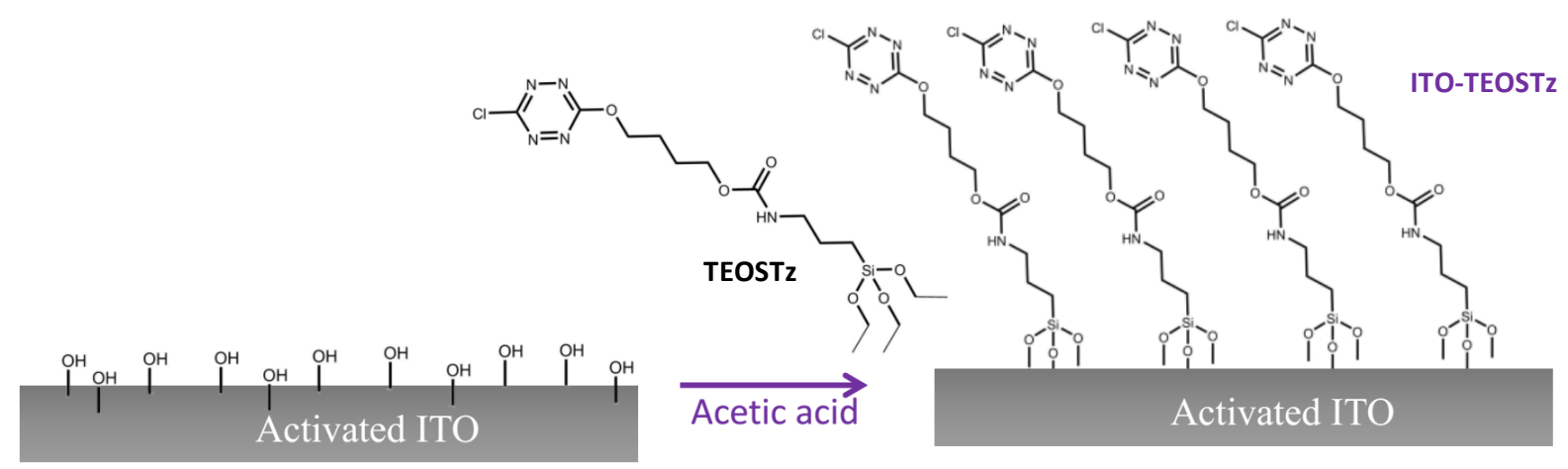

Scheme 1. Formation of tetrazine terminated alkyl chain monolayers on ITO.

The grafting of TEOSTz on ITO is first analyzed by ATR-FTIR. Figure 1 shows the ATR-IR spectra of TEOSTz as a pure liquid molecule, the hydrolyzed molecule after treatment by acetic acid in $\mathrm{CH}_{2} \mathrm{Cl}_{2}$ for $20 \mathrm{~h}$ and the monolayer grafted on ITO after hydrolysis (ITO-TEOSTz). The spectrum of the molecule exhibits the features of the carbamate moiety with $v_{\mathrm{C}=\mathrm{O}}\left(\mathbf{I}, 1716 \mathrm{~cm}^{-1}\right.$, strong $\left.(\mathrm{s})\right), \delta_{\mathrm{N}-\mathrm{H}}$ (II, $\left.1515 \mathrm{~cm}^{-1}, \mathrm{~s}\right), \delta_{\mathrm{C}-\mathrm{N}}+v_{\mathrm{CN}-\mathrm{H}}\left(\mathrm{III}, 1280 \mathrm{~cm}^{-1}\right.$, medium-weak $\left.(\mathrm{m}-\mathrm{w})\right), v_{\text {asc-O-C }}\left(1246 \mathrm{~cm}^{-1}\right.$, asym., s) $v_{\mathrm{C}-\mathrm{N}}+v_{\mathrm{C}-\mathrm{O}}+$ $\delta_{\mathrm{OCN}}+\delta_{\mathrm{C}-\mathrm{C}}\left(957 \mathrm{~cm}^{-1}, \mathrm{~s}\right)^{40}$, and also those of the alkyl chain with the $\delta_{\mathrm{CH} 2}\left(1460 \mathrm{~cm}^{-1}, \mathrm{~m}\right)$ bending vibration. The tetrazine group $(\mathrm{Tz})$ is evidenced by the cycle stretching bands at $\left(1498-92 \mathrm{~cm}^{-1}, \mathrm{~s}\right.$; $\left.1458 \mathrm{~cm}^{-1}, \mathrm{~m}\right)$, by the vibration $v_{\mathrm{T} z-0-\mathrm{C}}\left(1197 \mathrm{~cm}^{-1}\right.$, asym., $\left.\mathrm{m}\right)$ and also by the one at $780 \mathrm{~cm}^{-1}(\mathrm{~m})^{41}$. These latter bands do not vary much during the hydrolysis step.

The hydrolysis of the ethoxysilane groups is visible by the decrease of the $\delta_{\mathrm{OCH} 2}\left(1498 \mathrm{~cm}^{-1}\right.$, shoulder), $\delta \mathrm{CH}_{3}\left(1370 \mathrm{~cm}^{-1}\right.$, sym., $\left.m\right)$, the doublet $v_{\text {assi-o-Et }}\left(1103,1077 \mathrm{~cm}^{-1}\right.$, asym., s), $v_{\text {ssi-O-Et }}\left(935 \mathrm{~cm}^{-1}\right.$, sym, s-m) and $v_{\text {Si-O-Et }}\left(1037 \mathrm{~cm}^{-1}, \mathrm{~m}\right)^{42}$.

The adsorbed monolayer is hydrolyzed and condensed given the absence of the band at $1077 \mathrm{~cm}^{-1}$ and the appearance of a strong and broad band located at $1108 \mathrm{~cm}^{-1}$ and assigned to the Si-O-Si 
stretching ${ }^{1}$. Beside the $\mathrm{C}=\mathrm{O}$ band already seen in the pure molecule at $1716 \mathrm{~cm}^{-1}$, another band appears at $1680 \mathrm{~cm}^{-1}$ assigned to the $\mathrm{C}=\mathrm{O}$ group which has formed hydrogen bonds. In the same way, the $\delta_{\mathrm{NH}}$ band is shifted from $1532 \mathrm{~cm}^{-1}$ (molecule) to $1568 \mathrm{~cm}^{-1}$ (monolayer). This can account for the presence of strong hydrogen bonds between the $\mathrm{NH}$ group and the $\mathrm{C}-\mathrm{O}$ or $\mathrm{C}=\mathrm{O}$ groups. The $\mathrm{Tz}$ bands are globally unchanged upon grafting. From ATR-IR measurements it can be concluded that the monolayer is hydrolyzed and well condensed via the formation of Si-O-Si groups. The presence of strong hydrogen bonds mainly via the NH moiety is clearly connected to an organization of the chains of the TEOSTz molecules in the monolayer.

The modified ITO electrode ITO-TEOSTz is then characterized by cyclic voltammetry and emission spectrophotometry. The results are shown in figure 2. CV shows a symmetrical peak shape curve as expected for an electroactive molecule grafted on the electrode surface. The electrochemical signal is reversible, showing that the tetrazine moiety can be reduced into a stable anion radical likely to be reoxidized on the backward scan, like in solution. The amount of charge related to the redox conversion can be extracted by integration of the $\mathrm{CV}$ and allows estimating the coverage ratio ${ }^{43}$. $\mathrm{A}$ value of $100 \mu \mathrm{C}$ is obtained leading to a coverage of $2.210^{-10} \mathrm{~mol} \mathrm{~cm}^{2}$, consistent with the formation of a probably not densely packed monolayer if one refers to the corresponding value for ferrocene ${ }^{44}$. The half width of the redox peak is close to the theoretical $90 \mathrm{mV}$ expected for a monoelectronic charge transfer, showing that electrostatic interactions are negligible between charged species, which is consistent with a loosely packed configuration.

It is noticeable that the reduction peak of TEOSTz is accompanied by another reduction peak at more positive potentials which has been assigned to a proton assisted reduction (see below). The pre-peak involves the tetrazine moiety as it evolves the same way as the main reduction peak upon cycling.

The emission spectrum shows a broad band centered at $560 \mathrm{~nm}$, characteristic of the chloroalkoxytetrazine fluorophore ${ }^{45}$. This demonstrates that tetrazine still behaves as an electroactive fluorophore once grafted on the ITO surface. As the electrochemical signal is reversible, conditions are fulfilled to test the electrofluorochromic properties of the monolayer.

Figure 3 shows the fluorescence images (in false colors) and emission spectra when a potential signal made of successive steps between $0 \mathrm{~V}$ and $-0.65 \mathrm{~V}$ is applied. These two potential values belong to the stability range of the neutral and anion radical forms of the Tz derivative respectively. A clear contrast in the various images can be seen in fig. 3B but the difference in intensities remain small. Emission spectra in fig. $3 \mathrm{C}$ show various contributions coming from background (especially ITO itself). The magnitude of these contributions can be seen on blank experiments recorded on bare ITO but

\footnotetext{
${ }^{1}$ The accuracy of the wavenumbers of the grafted monolayer is $\pm 5 \mathrm{~cm}^{-1}$.
} 
without correlation with the electrode potential (see fig. S1). Despite this significant background contribution, when the electrode potential varies from 0 to $-0.65 \mathrm{~V}$ and back to $0 \mathrm{~V}$, clear variations in emission intensity can be seen in the wavelength range where Tz emits (530-615 nm). Subtraction of this background, corresponding to the emission spectrum after the potential of $-0.65 \mathrm{~V}$ is maintained so that all the Tz fluorophores have been reduced, allows one to extract the signal coming from the Tz monolayer alone (figure 3D). Now the variation of emission intensity assigned to the reduction and reoxidation of the Tz fluorophore can be clearly seen. It can be noticed that the emission intensity can be fully quenched upon reduction (red trace) but only partly recovered upon reoxidation (see green trace vs. blue trace). This is due to the fact that bleaching also contributes to quench the emission of the monolayer. This is especially evidenced by recording the raw emission intensity from integration of emission spectra between 530 and $615 \mathrm{~nm}$ during the same period of time as in the signal of figure 3A. The result is shown in figure 4 . In the time period when no potential modulation is applied, a gradual intensity drop is observed which can be modelled by an exponential decay. The potential modulation applied in the 15-20s, 30-35s and 45-50s time intervals shows the contribution of the electrochemical signal to quenching.

Although bleaching is an issue, its impact on the signal to noise ratio can be limited by normalizing the emission intensity vs. the values of the bleaching model curve (red line in figure 4). In absence of potential modulation, a baseline with values of 1 are expected, while applying a potential modulation leads to negative deviation from this baseline. The results are displayed in figure 5 for three successive steps between $0 \mathrm{~V}$ and $-0.65 \mathrm{~V}$. The emission signal (chronofluorogram) shows 'on-off-on' switches with the duration of the 'off' period consistent with the one when the negative potential is applied ( $5 \mathrm{~s}$ in the top, $10 \mathrm{~s}$ in the bottom). This shows the actual correlation between the electrochemical signal (potential steps) and the fluorescence intensity obtained by integration of emission spectra corrected from background and bleaching.

To further demonstrate that the emission signal of the monolayer can be fully controlled by the electrode potential, an experiment consisting of three successive steps of gradually more and more negative potential values have been applied, with the results shown in figure 6 . A clear variation of intensity is observed since the first potential step at $-0.2 \mathrm{~V}$, confirming that the reduction peak observed at that potential involves the tetrazine moiety, probably in a proton assisted reduction reaction similar to what happens with quinones. As the amount of protons is limited, an aprotic reduction leading to the formation of the anion radical also occurs at more negative values and is responsible for the deeper fluorescence drop observed upon the second potential step. The final step at $-0.65 \mathrm{~V}$, which is supposed to achieve the exhaustive reduction of all the fluorophores, leads to a less intense fluorescence drop because the previous backward steps did not succeed in restoring the 
emission intensity at the same level as before the step. However, this final potential step drives the emission down to zero.

To confirm the role played by the remaining acid, another set of experiments was conducted with a much lower amount of acetic acid (hundred times more diluted solution). The corresponding CV (see figure S2) shows a less pronounced first reduction peak which now appears as a shoulder of the main reduction peak. The set of fluorescence images and intensities when the potential varies according to a similar variation as in figure $3 \mathrm{~A}$ can be seen in figure $\mathrm{S} 3$. The amplitude of the fluorescence drop is the same for the three successive potential steps, when measured compared to the bleaching model curve. More interestingly, when applying gradually more and more negative potential values upon the three steps, as in figure 6, the corresponding emission intensity variation appears significantly different (figure 7). Now the amplitude of the emission drop increases as the potential decreases, as expected for a pure Nernstian electrochemical process where the electrode potential controls the ratio of oxidized and reduced forms at the electrode. Indeed, the first two potential steps only partly quench the emission while the last one, corresponding to the full electrochemical conversion, actually switches the emission down to zero. After each step the emission intensity is switched back to values close to the initial one, showing that the luminescence intensity of the monolayer can be tuned by the electrode potential almost at will. The only restriction is the stability of the system especially under illumination, which does not allow more than a few cycles to be applied.

\section{Conclusion}

Tetrazine functionalized monolayers have been grafted on ITO through siloxane anchoring groups. The resulting monolayers are electroactive and luminescent. The luminescence can be tuned electrochemically with a full contrast between the oxidized 'on' and the reduced 'off' states. The signal to noise ratio has been optimized by subtracting the contribution of ITO in the emission spectra. Thus we have shown that electrofluorochromic properties could be translated from solution to surface while keeping a full electrochemical control, despite limitation in the cyclability due to bleaching. For practical use, this might be overcome by designing thicker layers using for example a polymer matrix or diazonium grafting. Anyway it demonstrates that modified electrodes with a very small amount of electrofluorochromic molecules can be operated in devices like displays or sensors based on this principle. 


\section{References}

1. Al-Kutubi, H.; Zafarani, H. R.; Rassaei, L.; Mathwig, K., Electrofluorochromic systems: Molecules and materials exhibiting redox-switchable fluorescence. Eur. Polym. J. 2016, 83, 478-498. 2. Sun, J. W.; Chen, Y. N.; Liang, Z. Q., Electroluminochromic Materials and Devices. Adv. Funct. Mater. 2016, 26 (17), 2783-2799.

3. Miomandre, F.; Audebert, P., Luminescence in Electrochemistry. Springer: 2017.

4. Audebert, P.; Miomandre, F., Electrofluorochromism : from molecular systems to set-up and display. Chemical Science 2013, 4, 575-584.

5. Du, J.; Liao, R.; Zhang, X. L.; Sun, H. B.; Huang, W., The Classification of Electrofluorochromism Materials and Color Change Mechanisms. Prog. Chem. 2018, 30 (2-3), 286-294.

6. Miomandre, F.; Lepicier, E.; Munteanu, S.; Galangau, O.; Audibert, J. F.; Meallet-Renault, R.; Audebert, P.; Pansu, R. B., Electrochemical Monitoring of the Fluorescence Emission of Tetrazine and Bodipy Dyes Using Total Internal Reflection Fluorescence Microscopy Coupled to Electrochemistry. Acs Appl. Mat. Int. 2011, 3 (3), 690-696.

7. Beneduci, A.; Cospito, S.; La Deda, M.; Veltri, L.; Chidichimo, G., Electrofluorochromism in piconjugated ionic liquid crystals. Nature Communications 2014, 5.

8. Suleymanov, A. A.; Ruggi, A.; Planes, O. M.; Chauvin, A.-S.; Scopelliti, R.; Fadaei Tirani, F.;

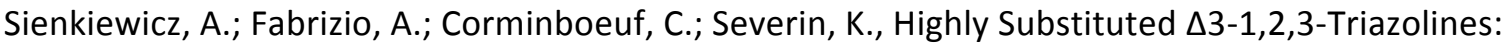
Solid-State Emitters with Electrofluorochromic Behavior. Chemistry - A European Journal 2019, 25 (27), 6718-6721.

9. $\quad$ Cheng, S. W.; Han, T.; Huang, T. Y.; Tang, B. Z.; Liou, G. S., High-performance electrofluorochromic devices based on aromatic polyamides with AIE-active tetraphenylethene and electro-active triphenylamine moieties. Polym. Chem. 2018, 9 (33), 4364-4373.

10. Sun, N. W.; Su, K. X.; Zhou, Z. W.; Yu, Y.; Tian, X. Z.; Wang, D. M.; Zhao, X. G.; Zhou, H. W.; Chen, C. H., AlE-Active Polyamide Containing Diphenylamine-TPE Moiety with Superior Electrofluorochromic Performance. Acs Applied Materials \& Interfaces 2018, 10 (18), 16105-16112. 11. Miomandre, F.; Allain, C.; Clavier, G.; Audibert, J.-F.; Pansu, R. B.; Audebert, P.; Hartl, F., Coupling thin layer electrochemistry with epifluorescence microscopy: An expedient way of investigating electrofluorochromism of organic dyes. Electrochem. Commun. 2011, 13 (6), 574-577. 12. Pak, F.; Meral, K.; Altundas, R.; Ekinci, D., Self-assembled monolayers of fluorene- and nitrofluorene-terminated thiols on polycrystalline gold electrode: Electrochemical and optical properties. J. Electroanal. Chem. 2011, 654 (1-2), 20-28.

13. Compton, R. G.; Fisher, A. C.; Wellington, R. G., A THIN-LAYER ELECTRODE CELL FOR FLUORESCENCE MEASUREMENTS ON ELECTROGENERATED INTERMEDIATES. Electroanalysis 1991, 3 (1), 27-29.

14. Dias, M.; Hudhomme, P.; Levillain, E.; Perrin, L.; Sahin, Y.; Sauvage, F. X.; Wartelle, C., Electrochemistry coupled to fluorescence spectroscopy :a new versatile approach. Electrochem. Commun. 2004, 6, 325-330.

15. Miomandre, F.; Meallet-Renault, R.; Vachon, J. J.; Pansu, R. B.; Audebert, P., Fluorescence microscopy coupled to electrochemistry: a powerful tool for the controlled electrochemical switch of fluorescent moleculesw. Chem. Commun. 2008, 16, 1913.

16. Bouffier, L.; Doneux, T., Coupling electrochemistry with in situ fluorescence (confocal) microscopy. Current opinion in electrochemistry 2017, htpp://dx.doi.org/10.1016/j.coelec.2017.06.015.

17. Lei, C.; Hu, D.; Ackerman, E. J., Single molecule fluorescence spectroelectrochemistry of cresyl violet. Chem. Commun. 2008, 5490-5492.

18. Doppagne, B.; Chong, M. C.; Bulou, H.; Boeglin, A.; Scheurer, F.; Schull, G., Electrofluorochromism at the single-molecule level. Science 2018, 361 (6399), 251-254.

19. Montilla, F.; Frutos, L. M.; Mateo, C. R.; Mallavia, R., Fluorescence emission anisotropy coupled to an electrochemical system: Study of exciton dynamics in conjugated polymers. J. Phys. Chem. C 2007, 111 (49), 18405-18410. 
20. You, J.; Kim, Y.; Kim, E., Electrochemical Fluorescence Switching from Anthracene Polymer Films. Mol. Cryst. Liq. Cryst. 2010, 520, 404-411.

21. Kim, Y.; Kim, J.; You, J.; Kim, E., Electrochemical Modulation of Color and Fluorescence in One Cell Using Conducting Polymers. Molecular Crystals and Liquid Crystals 2011, 538, 39-44.

22. Montilla, F.; Mallavia, R., In situ electrochemical fluorescence studies of PPV. J. Phys. Chem. B 2006, 110, 25791-25796.

23. Sun, N. W.; Meng, S. Y.; Zhou, Z. W.; Yao, J. N.; Du, Y. L.; Wang, D. M.; Zhao, X. G.; Zhou, H. W.; Chen, C. H., High-contrast electrochromic and electrofluorescent dual-switching materials based on 2-diphenylamine-(9,9-diphenylfluorene)-functionalized semi-aromatic polymers. Rsc Advances 2016, 6 (70), 66288-66296.

24. Sun, J. W.; Liang, Z. Q., Swift Electrofluorochromism of Donor-Acceptor Conjugated Polytriphenylamines. ACS Appl. Mater. Int. 2016, 8 (28), 18301-18308.

25. Lin, H.-T.; Huang, C.-L.; Liou, G.-S., Design, Synthesis, and Electrofluorochromism of New Triphenylamine Derivatives with AIE-Active Pendent Groups. ACS Appl. Mater. Int. 2019, 11 (12), 11684-11690.

26. Sun, N.; Su, K.; Zhou, Z.; Tian, X.; Jianhua, Z.; Chao, D.; Wang, D.; Lissel, F.; Zhao, X.; Chen, C., High-Performance Emission/Color Dual-Switchable Polymer-Bearing Pendant Tetraphenylethylene (TPE) and Triphenylamine (TPA) Moieties. Macromolecules 2019, 52 (14), 5131-5139.

27. Lei, C. H.; Hu, D. H.; Ackerman, E., Clay Nanoparticle-Supported Single-Molecule Fluorescence Spectroelectrochemistry. Nano Lett. 2009, 9 (2), 655-658.

28. Seo, S.; Allain, C.; Na, J.; Kim, S.; Yang, X.; Park, C.; Malinge, J.; Audebert, P.; Kim, E., Electrofluorescence switching of tetrazine-modified TiO2 nanoparticles. Nanoscale 2013, 5 (16), 7321-7327.

29. Bkhach, S.; Aleveque, O.; Blanchard, P.; Gautier, C.; Levillain, E., Thienylene vinylene dimerization: from solution to self-assembled monolayer on gold. Nanoscale 2018, 10 (4), 1613-1616. 30. Murphy, J. N.; Cheng, A. K. H.; Yu, H. Z.; Bizzotto, D., On the Nature of DNA Self-Assembled Monolayers on Au: Measuring Surface Heterogeneity with Electrochemical in Situ Fluorescence Microscopy. Journal of the American Chemical Society 2009, 131 (11), 4042-4050.

31. Meunier, A.; Triffaux, E.; Bizzotto, D.; Buess-Herman, C.; Doneux, T., In Situ Fluorescence Microscopy Study of the Interfacial Inhomogeneity of DNA Mixed Self-Assembled Monolayers at Gold Electrodes. ChemElectroChem 2015, 2 (3), 434-442.

32. Rivera-Gandia, J.; Georgiadis, R. M.; Cabrera, C. R., In-situ fluorescence spectroscopy of selfassembled monolayers of HS-(CH2)(n)-fluorescein and HS-(CH2)(6)-poly(dT)(18)-fluorescein at gold electrodes under cyclic voltammetric conditions. J. Electroanal. Chem. 2008, 621 (1), 75-82.

33. Casanova-Moreno, J. R.; Bizzotto, D., What Happens to the Thiolates Created by Reductively Desorbing SAMs? An in Situ Study Using Fluorescence Microscopy and Electrochemistry. Langmuir 2013, 29 (6), 2065-2074.

34. Shepherd, J. L.; Kell, A.; Chung, E.; Sinclar, C. W.; Workentin, M. S.; Bizzotto, D., Selective reductive desorption of a SAM-coated gold electrode revealed using fluorescence microscopy. Journal of the American Chemical Society 2004, 126 (26), 8329-8335.

35. Clavier, G.; Audebert, P., s-Tetrazines as Building Blocks for New Functional Molecules and Molecular Materials. Chemical Reviews 2010, 110 (6), 3299-3314.

36. Kim, Y.; Kim, E.; Clavier, G.; Audebert, P., New tetrazine-based fluoroelectrochromic window : modulation of the fluorescence through applied potential. Chem. Commun. 2006, 3612-3614.

37. Jaiswal, S.; Varma, P. C. R.; Mutuma, F.; McHale, P.; Duffy, B., Protective properties of functionalised tetrazine on an aerospace aluminium alloy (AA 2024-T3). Materials Chemistry and Physics 2015, 163, 190-200.

38. Skomski, D.; Tempas, C.; Polezhaev, A.; Cook, B.; Man, J.; Tait, S.; Caulton, K., Redox active ligand design on a surface: Synthesis and characterization of tetrazine complexes of $\mathrm{Pt}, \mathrm{V}$, and $\mathrm{Nb}$ from metal atoms. Abstracts of Papers of the American Chemical Society 2015, 250. 
39. Malinge, J.; Allain, C.; Galmiche, L.; Miomandre, F.; Audebert, P., Preparation, Photophysical, Electrochemical, and Sensing Properties of Luminescent Tetrazine-Doped Silica Nanoparticles. Chem. Mater. 2011, 23 (20), 4599-4605.

40. Furer, V. L., Calculation of the IR spectra of toluene-2,4-bis (methyl) carbamate. Journal of Molecular Structure 1999, 476, 215-222.

41. Li, Y.; Alain-Rizzo, V.; Galmiche, L.; Audebert, P.; Miomandre, F.; Louarn, G.; Bozlar, M.; Pope, M. A.; Dabbs, D. M.; Aksay, I. A., Functionalization of Graphene Oxide by Tetrazine Derivatives: A Versatile Approach toward Covalent Bridges between Graphene Sheets. Chemistry of Materials 2015, 27 (12), 4298-4310.

42. Socrates, G., IR and Raman characteristics Group frequencies. Wiley and sons: 2001; Vol. 3rd edition.

43. Eckermann, A. L.; Feld, D. J.; Shaw, J. A.; Meade, T. J., Electrochemistry of redox-active selfassembled monolayers. Coordination Chemistry Reviews 2010, 254 (15), 1769-1802.

44. Gui, J. Y.; Stern, D. A.; Lu, F.; Hubbard, A. T., Surface chemistry of five-membered heteroaromatics at Pt(III) electrodes studied by EELS, LEED, Auger spectroscopy and electrochemistry: furan, pyrrole and thiophene. Journal of Electroanalytical Chemistry and Interfacial Electrochemistry 1991, 305 (1), 37-55.

45. Qing, Z.; Audebert, P.; Clavier, G.; Miomandre, F.; Tang, J.; Vu, T. T.; Meallet-Renault, R., Tetrazines with hindered or electron withdrawing substituents: Synthesis, electrochemical and fluorescence properties. Journal of Electroanalytical Chemistry 2009, 632 (1-2), 39-44. 


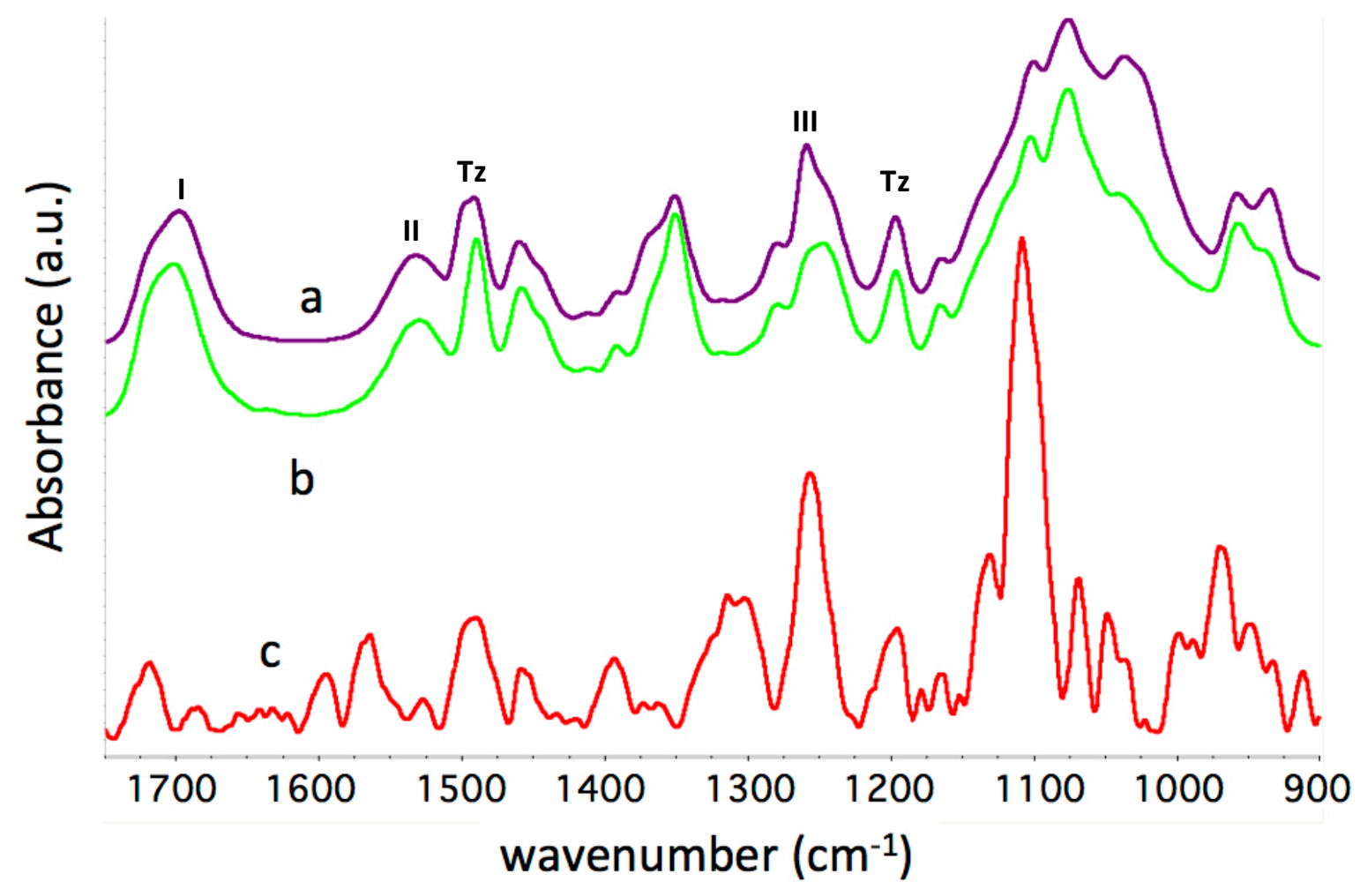

ATR-IR spectra of TEOSTz: a (top): pure liquid molecule; $\mathbf{b}$ (middle): after hydrolysis; $\mathbf{c}$ (bottom): after the adsorption/grafting onto ITO substrate 
Figure 2
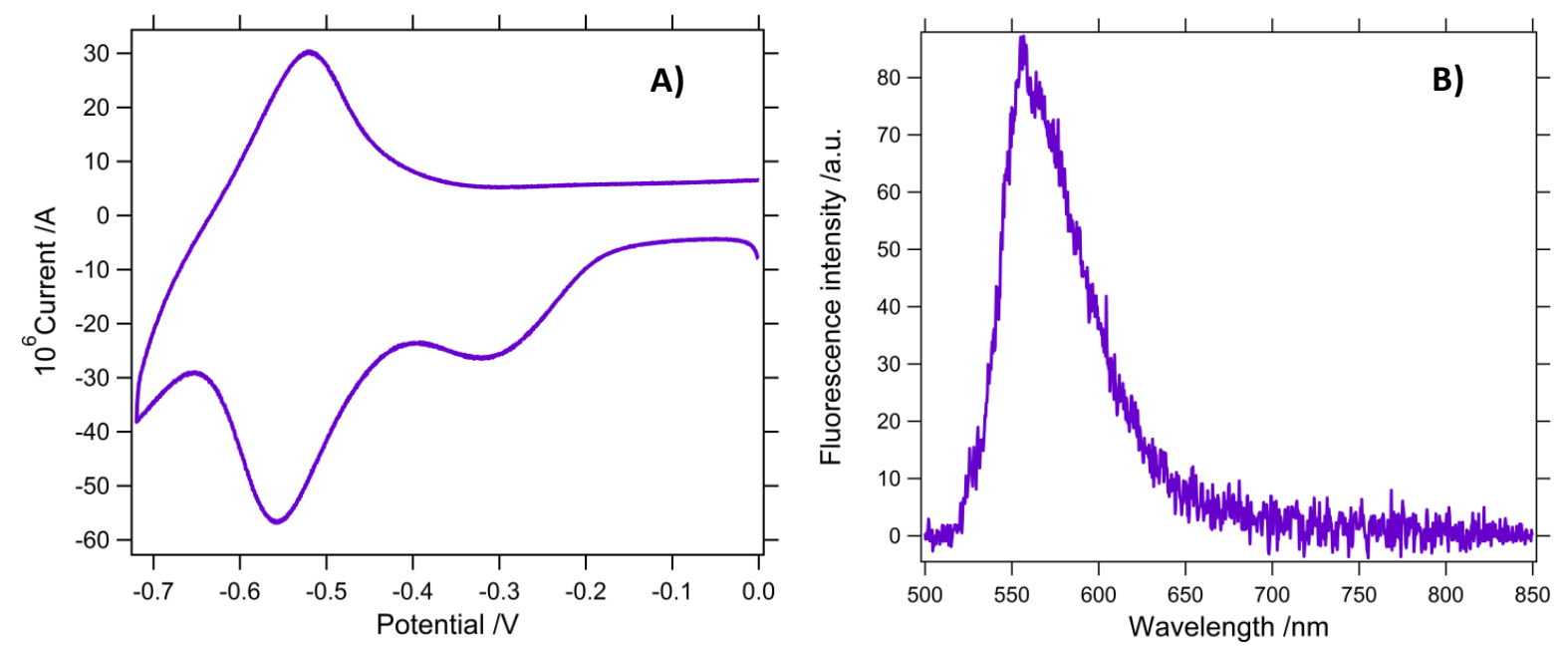

A) CV of ITO-TEOSTz in dichloromethane + TBAPF $_{6} 0.1 \mathrm{M}$ at $100 \mathrm{mV} / \mathrm{s}$.

B) Emission spectrum of ITO-TEOSTz (excitation wavelength : $482 \mathrm{~nm}$ ) recorded with the fluorescence microscope, after subtracting a blank made of a long irradiated sample under polarization. 
Figure 3
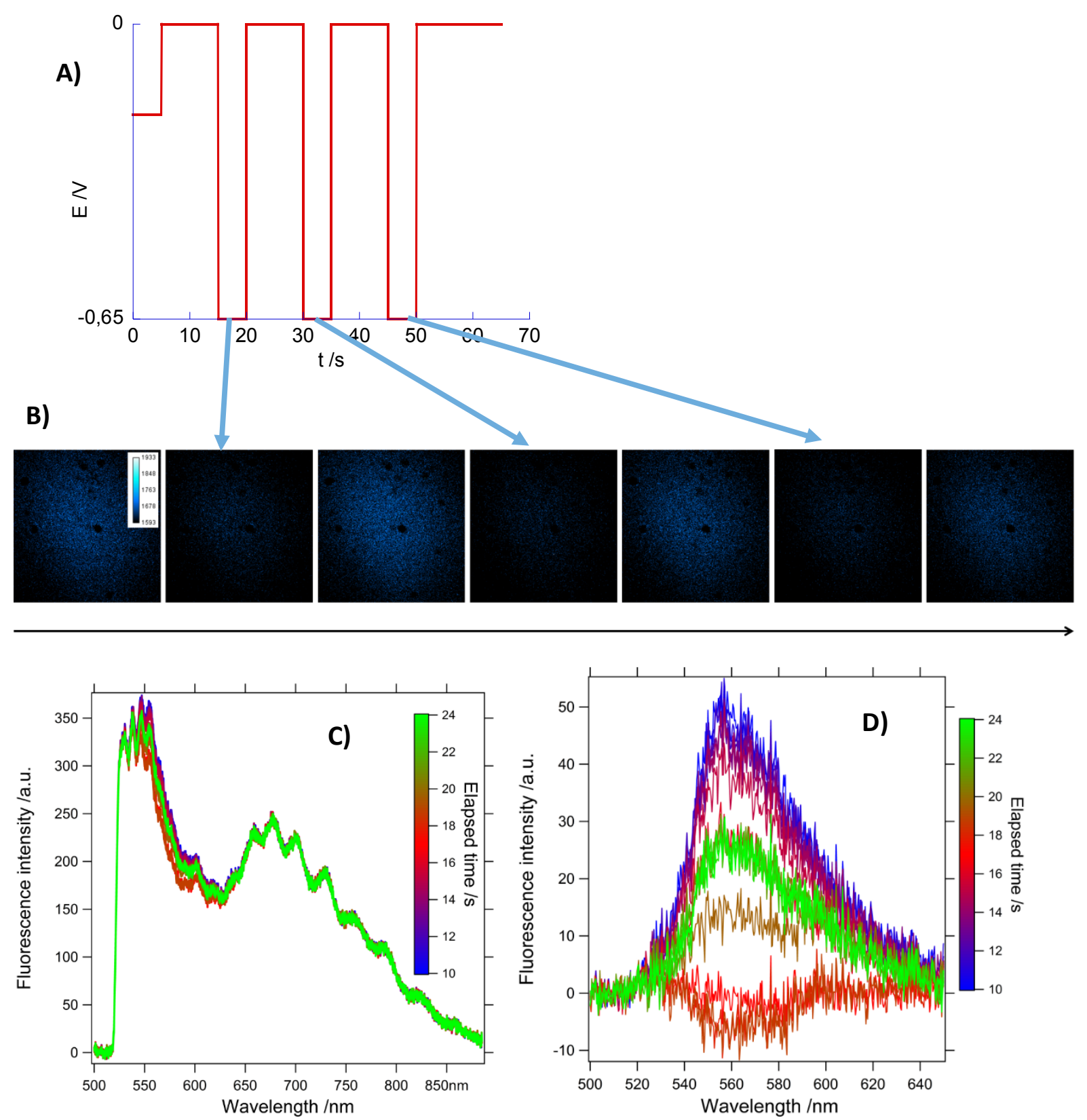

Fluorescence images recorded at various timeframes (B) for the potential signal shown in A).

Variation of fluorescence spectra with time in the 10-25s range: raw signal (C) and signal corrected from background (D). 
Figure 4

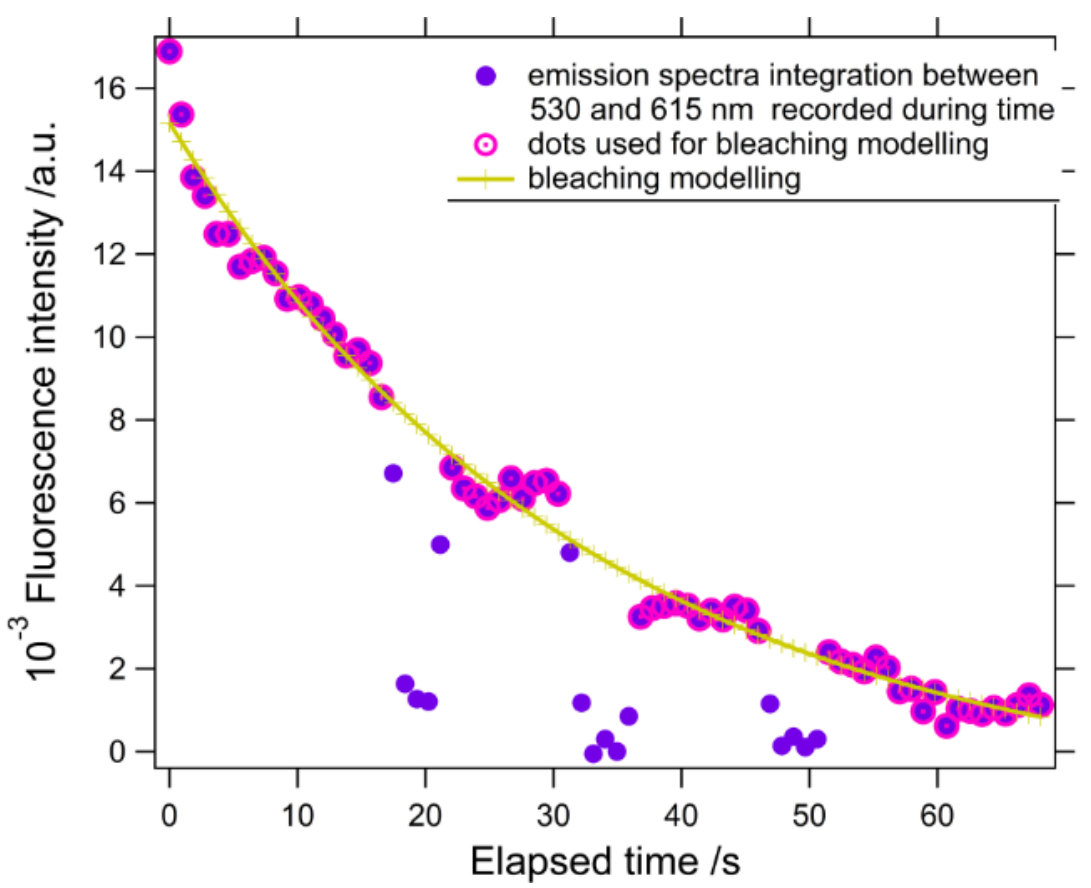

Fluorescence intensity obtained by integration of emission spectra between 530 and $615 \mathrm{~nm}$ (blue dots) along with bleaching model (pink dots and yellow line). 
Figure 5

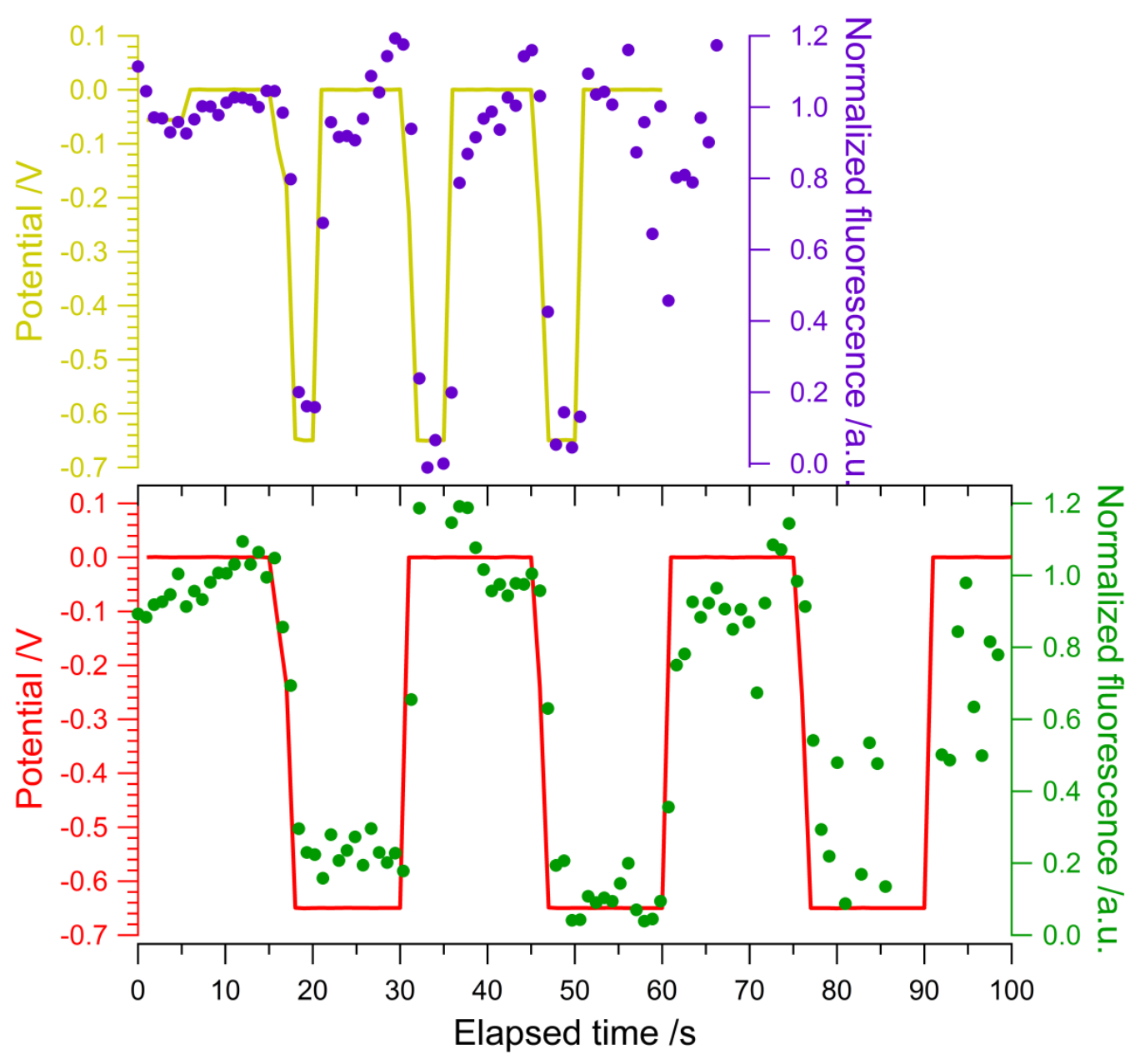

Chronofluorograms obtained by integration of emission spectra between 530 and $615 \mathrm{~nm}$ and corrected from background and bleaching (purple or green dots) for the potential signals shown (yellow and red lines). The duration of the 'off' state $(-0.65 \mathrm{~V})$ is $5 \mathrm{~s}$ (top) or $10 \mathrm{~s}$ (bottom) while the duration of the 'on' state is $10 \mathrm{~s}$ (top) or $15 \mathrm{~s}$ (bottom). 
Figure 6

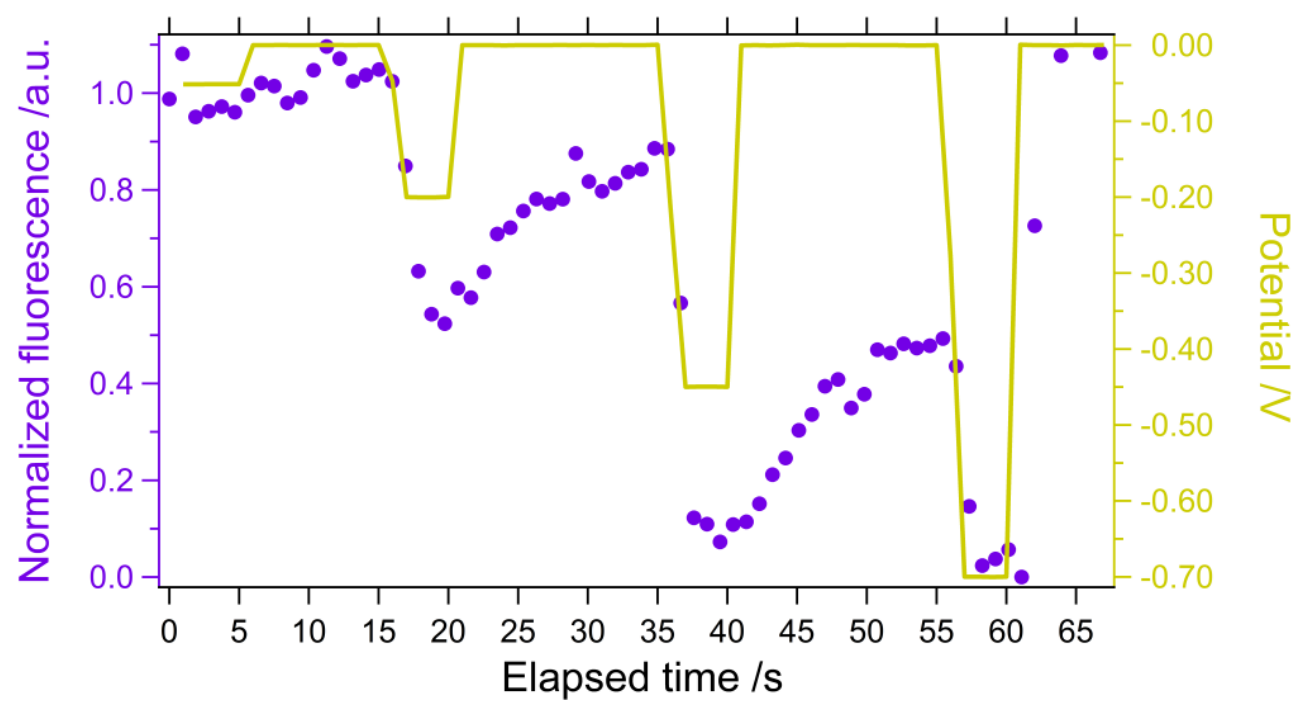

Chronofluorogram obtained by integration of emission spectra between 530 and $615 \mathrm{~nm}$ and corrected from background and bleaching (purple dots) for the potential signal shown in yellow and corresponding to the following sequence: OC (5 s), $0 \vee(10 s),-0,2 \vee(5 s), 0 \vee(15 s),-0,45 \vee(5 s), 0 V$ $(15 s),-0,7(5 s), 0 \vee(10 s)$. 
Figure 7

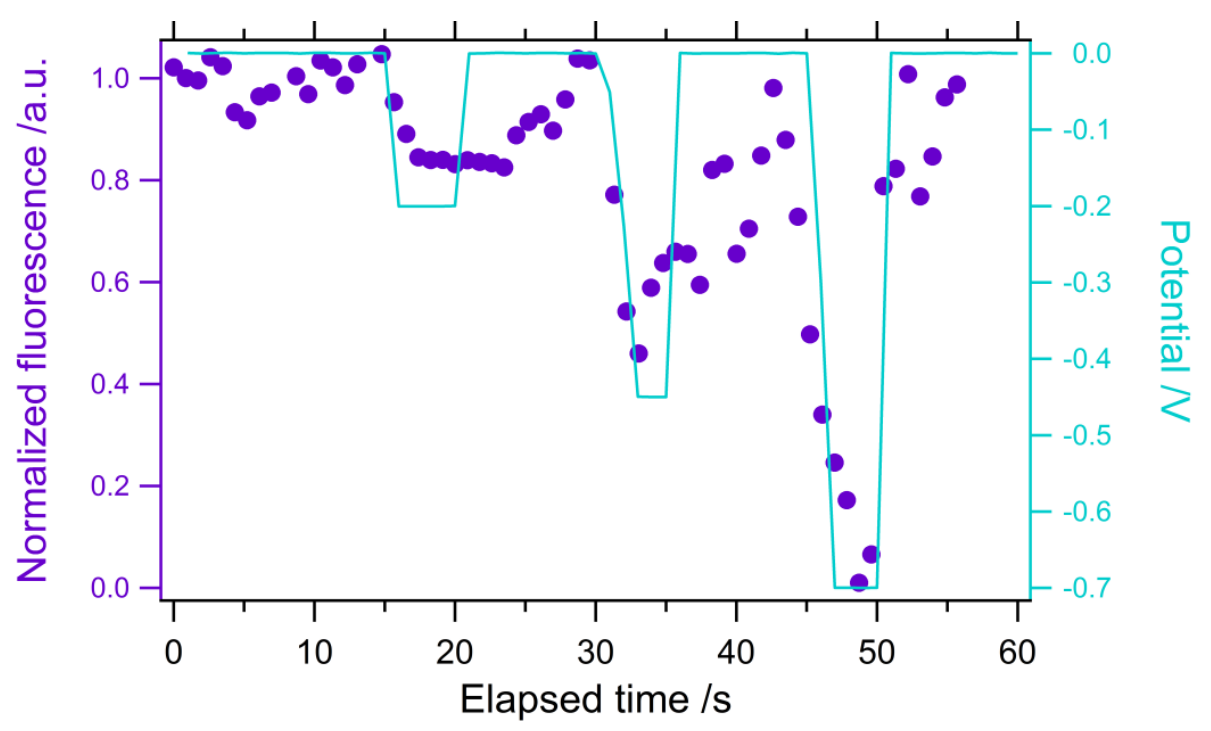

Same experiment as in figure 6 for a hundred time more diluted acid solution 